\title{
Adrenal cortical tumors, pheochromocytomas and paragangliomas
}

\author{
Ricardo V Lloyd \\ Department of Pathology, University of Wisconsin School of Medicine and Public Health, Madison, WI, USA
}

\begin{abstract}
Distinguishing adrenal cortical adenomas from carcinomas may be a difficult diagnostic problem. The criteria of Weiss are very useful because of their reliance on histologic features. From a practical perspective, the most useful criteria to separate adenomas from carcinomas include tumor size, presence of necrosis and mitotic activity including atypical mitoses. Adrenal cortical neoplasms in pediatric patients are more difficult to diagnose and to separate adenomas from carcinomas. The diagnosis of pediatric adrenal cortical carcinoma requires a higher tumor weight, larger tumor size and more mitoses compared with carcinomas in adults. Pheochromocytomas are chromaffin-derived tumors that develop in the adrenal gland. Paragangliomas are tumors arising from paraganglia that are distributed along the parasympathetic nerves and sympathetic chain. Positive staining for chromogranin and synaptophysin is present in the chief cells, whereas the sustentacular cells are positive for $\mathrm{S} 100$ protein. Hereditary conditions associated with pheochromocytomas include multiple endocrine neoplasia 2A and 2B, Von Hippel-Lindau disease and neurofibromatosis I. Hereditary paraganglioma syndromes with mutations of SDHB, SDHC and SDHD are associated with paragangliomas and some pheochromocytomas.
\end{abstract}

Modern Pathology (2011) 24, S58-S65; doi:10.1038/modpathol.2010.126

Keywords: adrenal cortical adenoma; adrenal cortical carcinoma; paraganglioma; pheochromocytoma; succinic dehydrogenase mutations

\section{Adrenal cortical tumors}

The normal adrenal contains three zones in the cortex (glomerulosa, fasciculata and reticularis), whereas the adrenal medulla is located in the central portion of the gland.

Adrenal cortical adenomas (Figure 1a) commonly arise from the zona fasciculata, although all three zones can give rise to benign or malignant tumors. Adrenal cortical adenomas may be functioning or nonfunctioning. ${ }^{1}$ These tumors are usually positive for melan A by immunostaining (Figure 1b). ${ }^{1}$ Many small adenomas $<3 \mathrm{~cm}$ in diameter are discovered accidentally during working up for various other conditions. These tumors are referred to as incidentalomas'. One of the major problems in diagnostic endocrine pathology is distinguishing adrenal cortical adenomas from carcinomas. This is especially true with borderline lesions compared with

Correspondence: Dr RV Lloyd, MD, PhD, University of Wisconsin School of Medicine and Public Health, K4/814 Clinical Science Center, 600 Highland Avenue, Madison, WI 53792, USA.

E-mail: rvlloyd@wisc.edu

Received 9 June 2010; accepted 10 June 2010 small adenomas $<20 \mathrm{~g}$ or very large tumors $>500 \mathrm{~g}$ that are usually obvious carcinomas.

Adrenal cortical carcinoma may be functioning malignancies in some cases, whereas in other cases they are nonfunctioning. ${ }^{1-6}$ The gross appearance of adrenal cortical carcinoma can be very helpful in making the diagnosis. Most carcinomas in adults are $>100 \mathrm{~g}$, whereas adenomas generally weigh $50 \mathrm{~g}$ or less. Adrenal cortical tumors weighing $<50 \mathrm{~g}$ have, on occasion, metastasized, but this is extremely uncommon. In pediatric patients, however, adrenal cortical adenomas may weigh up to $500 \mathrm{~g}$. In addition to tumor weight, the presence of necrosis usually indicates an adrenal cortical carcinoma unless the necrosis resulted from a traumatic insult such as FNA. A variegated appearance with nodularity and intersecting fibrous bands should also suggest the possibility of a carcinoma.

Various studies have outlined specific criteria used to diagnose adrenal cortical carcinomas. ${ }^{7-10}$ The criteria of Weiss ${ }^{8,9}$ are most useful because of their reliance on histologic features. These include high nuclear grade, mitotic rate $>5$ per $50 \mathrm{HPF}$, atypical mitotic figures, eosinophilic tumor cells ( $\geq 75 \%$ of tumor), diffuse architecture $(\geq 33 \%$ of tumor), necrosis, venous invasion (smooth muscle 

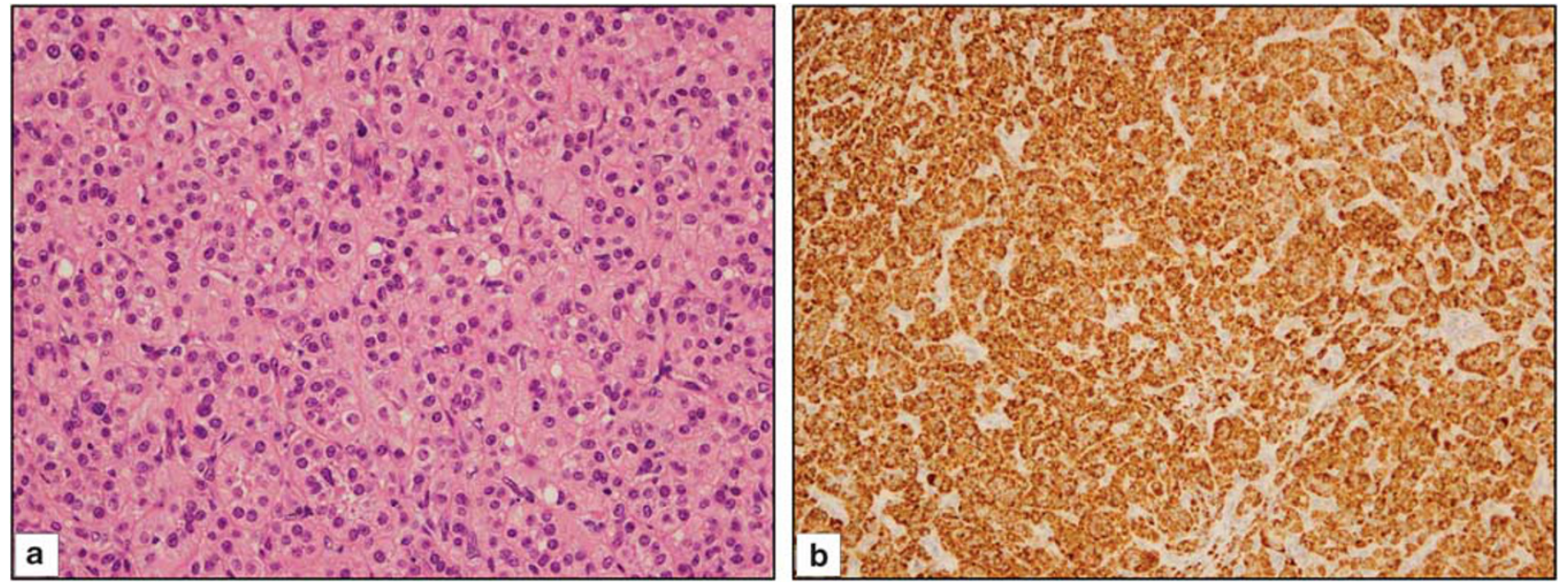

Figure 1 Adrenal cortical adenoma. (a) The tumor is composed of relatively uniform cells without mitosis or necrosis. (b) Melan-A immunostaining shows diffuse positive staining in the cytoplasm of the tumor cells.
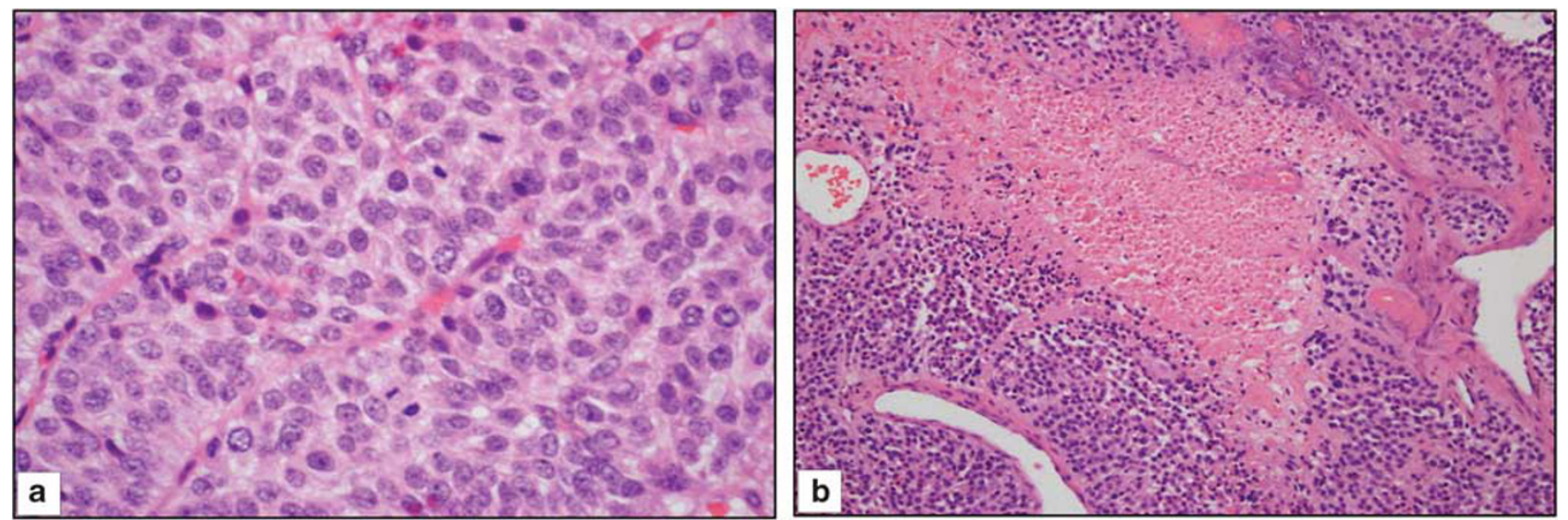

Figure 2 Adrenal cortical carcinoma. (a) The tumor cells have large nuclei and prominent nucleoli. Prominent mitotic figures are seen. (b) Confluent areas of necrosis are present in this adrenal cortical carcinoma.

in wall), sinusoidal invasion (no smooth muscle in wall) and capsular invasion ${ }^{8,9}$ (Figure 2a and b).

Three or more of the nine criteria are indicative of an adrenal cortical carcinoma, whereas two or less would be more in keeping with an adenoma. The modification of the Weiss system by Aubert et $a 1^{10}$ has somewhat simplified the Weiss criteria. Other systems such as that of van Slooten et $a l^{11}$ attach numeric values to the various criteria, and an index of eight or higher was consistent with a carcinoma.

One of the older systems is that of Hough et al, ${ }^{12}$ who used histologic criteria and clinical parameters in their assessment of adrenal cortical neoplasms. A numeric value of 2.91 was indicative of malignancy, whereas a value of 0.17 or less was consistent with a benign lesion. The disadvantage of this system is the reliance on clinical parameters as well as histologic features, and some of these clinical parameters, may not be available when examining the specimen.

From a practical perspective, the most useful criteria to separate adenomas from carcinomas include tumor size, presence of necrosis, mitotic activity including atypical mitoses, invasive growth and high nuclear grade. Capsular invasion may be difficult to recognize because the expanding capsule may be a preexisting adrenal capsule. Invasion of adjacent soft tissue, kidney or liver is definitive sign of malignancy. Special studies may be useful in confirming the nature of the malignant tissue. ${ }^{13-19}$ Ultrastructural studies may show the distinct features of ACC tissues including abundant smooth endoplasmic reticulum and mitochondria with prominent tubular or vesicular cristae. Immunohistochemical studies that are most useful in adrenal cortical carcinoma include melan A, inhibin- $\alpha$ and calretinin. Stains for cytokeratin are usually weakly positive, whereas vimentin is strongly positive. Synaptophysin is usually weakly positive in these tumors. Chromogranin is consistently negative. A marker for adrenal cortical cells, Ad4BP/SP-1, is relatively restricted in its distribution $^{20,21}$ and may be useful in the diagnosis of 
adrenal cortical tissues. This protein is a transcription factor that is needed for embryonic development of adrenal cortical cells.

Adrenal cortical neoplasm in pediatric patients is more difficult to diagnose and to separate adenomas from carcinomas. ${ }^{22}$ In a study of 83 adrenal cortical neoplasms, only $31 \%$ of histologically malignant tumors behaved in a clinically malignant manner. Features of malignancy included tumor weight $>400 \mathrm{~g}$, tumor size $>10.5 \mathrm{~cm}$, vena cava invasion, confluent necrosis, periadrenal soft tissue invasion $>15$ mitoses per HPF and atypical mitoses.

There are several variants of adrenal cortical tumors. The most common include the oncocytic tumors ${ }^{23,24}$ and the myxoid variant. ${ }^{25}$ Criteria for the diagnosis of oncocytic carcinomas were recently proposed by Weiss' group. ${ }^{24}$ Major criteria for oncocytic tumors included high mitotic rate, atypical mitoses and vena cava invasion. Minor criteria included large size and weight, necrosis, capsular invasion and sinusoidal invasion. One major criterion indicated malignancy, whereas 1-4 minor criteria indicated borderline tumors. Absence of all major and minor criteria indicated benign oncocytic tumors. The myxoid variant of adrenal cortical tumors looks different morphologically, but the criteria for malignancy should be similar to conventional adrenal cortical tumors.

The differential diagnosis of adrenal cortical carcinoma includes renal cell carcinoma, hepatocellular carcinoma, pheochromocytomas, and metastatic carcinomas and melanomas. Insulin-like growth factor-2 has been useful in the classification of adrenal cortical tumors. ${ }^{26}$

Recent studies of these various markers and techniques separate adrenal cortical carcinomas from adenomas. Some of these include DNA flow cytometric analysis and nucleolar organizer regions have not been very effective. However, some markers of proliferation have been shown to be useful in the distinction. Ki-67 labeling index with MIB-1 antibody are somewhat promising. ${ }^{19,20}$

\section{Molecular Studies}

Molecular studies have characterized various genes that are differentially expressed in normal and benign compared with malignant adrenal cortical tumors. ${ }^{27-31}$ The phenotypes of Ki-67-negative, p53negative, mdm-2-positive, cyclin-D1-negative, Bcl2-negative, p21-negative and p27-positive cells were found in $83 \%$ of normal adrenal tissues, but only in $3 \%$ of malignant tumors. ${ }^{27}$ Giordano and colleagues $^{28,29}$ performed microarray analysis of adrenal cortical tumors and reported upregulation of IGF2 in $10 \%$ of adrenal cortical carcinomas $(90.9 \%)$. Proliferation in related genes such as TOP2A and Ki-67 was also upregulated in carcinomas. VelazquezFernandez et $a l^{30}$ performed expression profiling of 7 patients with adrenal cortical carcinomas and 13 with adenomas and reported upregulation of ubiquitin-related genes (USP4 and UFD1L) and insulinlike growth factor-related genes (IGF2, IGF2R, $I G F \beta P 3$ and IGFBP6). A cytokine gene (CXCL10) and cadherin 2 gene $(\mathrm{CDH} 2)$ were downregulated in carcinomas compared with adenomas. ${ }^{30}$

\section{Pheochromocytomas and paragangliomas}

Pheochromocytomas ('dusky colored tumor') are chromaffin-derived tumors that develop in the adrenal gland. ${ }^{1}$ When the tumor is immersed in chromaffin salts or other weak oxidizing agents, it develops the dusky color. Most tumors are sporadic and benign. The reported incidence is about 0.4-9.5 per $10^{6}$ people. The tumors occur most frequently in the fourth and fifth decades. Familial tumors develop at a younger age. Most familial tumors are bilateral, whereas sporadic tumors are unilateral.

Patients usually present with throbbing headaches, sweating, palpitations, chest and abdominal pains. The 'spells' may last from 10 to $60 \mathrm{~min}$ and may be triggered by positional changes.

Pheochromocytomas usually form cell nests composed of cells with abundant basophilic cytoplasm (Figure 3a). Ultrastructural features include dense core secretory granules (Figure $3 b$ ).

Malignant pheochromocytomas comprise only about $10 \%$ of all pheochromocytomas. Signs and symptoms are similar to these in patients with benign disease; however, catecholamine production and the degree of hypertension may be more marked with metastatic disease.

Imaging studies cannot distinguish benign from malignant pheochromocytomas unless there is metastatic disease. CT studies and iodine-123-metaiodobenzyl-guanidine is very useful in imaging especially for locally recurrent or metastatic disease.

Malignant pheochromocytomas tend to be larger tumors than benign ones. They may be more nodular, lobular and show areas of necrosis. They may infiltrate periadrenal adipose tissue. Metastatic disease is the most reliable evidence of malignancy. ${ }^{31-45}$

Histologic features suggesting malignancy include capsular invasion, vascular invasion, extension into periadrenal adipose tissue, diffuse growth, necrosis, tumor cell spindling, increased cellularity, marked nuclear pleomorphism, macronucleoli, increased mitoses including atypical mitoses, absence or decreased hyaline globules.

Sustentacular cells were reported to be decreased or absent in malignant pheochromocytomas. ${ }^{1}$ MIB-1 labeling index may be helpful in separating benign and malignant pheochromocytomas. However, in some larger studies using 2.5 or $3.0 \%$ of cutoff points had a sensitivity of only $50 \%$ in identifying proven malignant tumors.

The Pheochromocytomas of the Adrenal Gland Scaled Score (PASS) was developed by Thompson to distinguish benign from malignant 

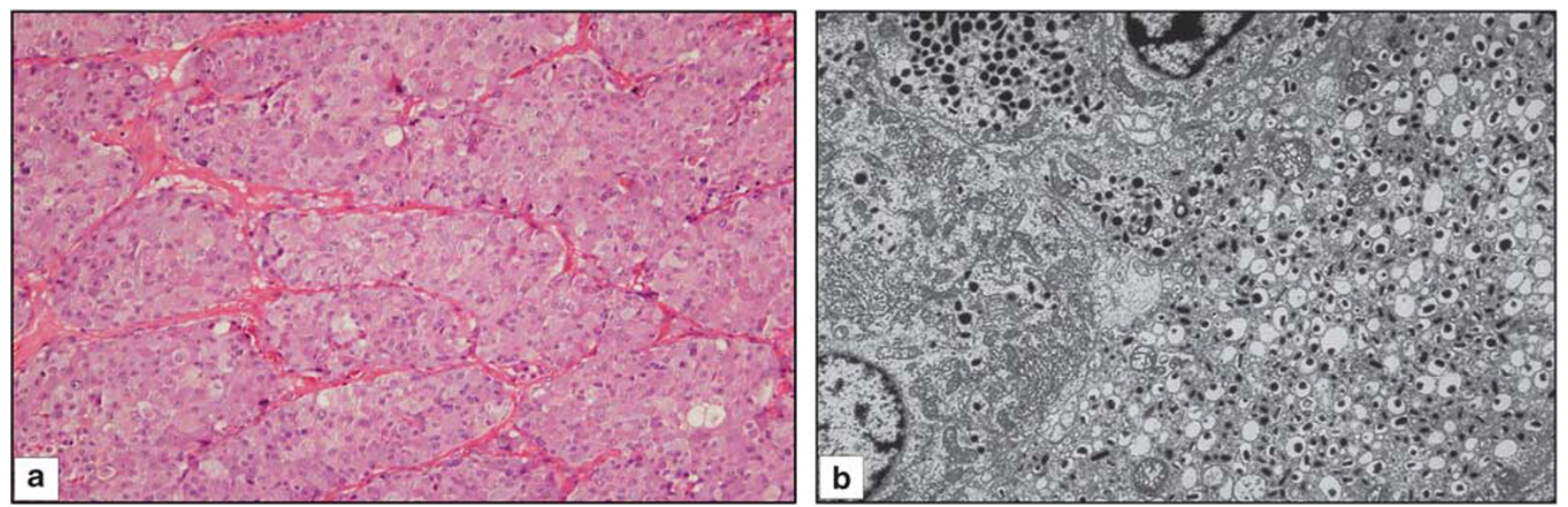

Figure 3 Pheochromocytoma. (a) The tumor cells have abundant basophilic cytoplasm. A prominent cell-nesting pattern (Zellballen) is noted. (b) Ultrastructural features of a pheochromocytoma with abundant secretory granules. The nonepinephrine-containing granules have a halo between the dense core and the granule membrane.

pheochromocytomas. ${ }^{46}$ It uses features such as growth pattern, necrosis, cellularity, cellular monotony, tumor cell spindling, mitotic count, atypical mitosis, invasion, nuclear pleomorphism and hyperchromasia to try to separate tumors. A PASS of $\geq 4$ is associated with a higher probability for malignancy. The use of the PASS was not validated independently in a recent study by a group of endocrine pathologists. ${ }^{47}$ Other studies of malignant pheochromocytomas have been recently reported. $^{34,48-50}$ The proposed system of Kimura et $a l^{34}$ used an assigned score that adds up to a maximum of 10 Ki-67 immunoreactivity along with catecholamine and phenotype. With a score of $7-10,100 \%$ of patients were found to have malignant tumors. ${ }^{34}$

Paragangliomas (PGLs) are tumors arising from the paraganglia that are distributed along the parasympathetic nerves in the head, neck and mediastinum, and along the sympathetic chain such as the cervical, intrathoracic, supraneural inferior paraaortic and urinary bladder. Although morphologic distinction between pheochromocytomas and PGLs is difficult, molecular differences between tumors arising in the adrenal medulla and other sites are more evident. As to malignancy, the general impression is that tumors arising in the organs of Zuckerkandl close to the bifurcation of the aorta have the highest incidence of malignancy.

Histopathologic features of pheochromocytomas and PGLs include chief cells with basophilic to amphophilic cells with abundant cytoplasm and large vesicular nuclei (Figure 4a). A prominent Zellballen or cell-nesting pattern may be present. Some tumors may have scant cytoplasm. Cellular and nuclear pleomorphism may be prominent. Cytoplasmic hyaline globules are frequently present. Melanin-like pigment may be present. Mitotic figures are uncommon. Tumors may have scattered ganglion cells, which does not indicate a composite tumor.

Immunohistochemical studies show that the chief cells of the tumors are positive for chromogranin
(Figure 4b) and synaptophysin (Figure 4c). The sustentacular cells are positive for S100 acidic protein (Figure 4d). The absence of positivity for EMA helps to distinguish pheochromocytomas from renal cell carcinomas. Adrenal cortical tumors are positive for melan A, inhibin- $\alpha$ and calretinin, and weakly positive for keratin; but negative for chromogranin A, whereas pheochromocytomas and PGLs are positive for chromogranin A and negative for melan A and keratins.

\section{Molecular Genetics}

Pheochromocytomas associated with a variety of inherited conditions including multiple endocrine neoplasia type 2 (MEN2), Von Hippel-Lindau (VHL) disease, neurofibromatous type 1 (NF1), heredity PGL syndromes and Sturge-Weber disease. The genetics of these disorders are summarized in Table $1 .{ }^{51}$

\section{Multiple endocrine neoplasia type 2}

Approximately $50 \%$ of patients with MEN2 develop pheochromocytomas. De novo germ-line mutations occur in about $6 \%$ of MEN2A and familial medullary thyroid carcinoma cases and in around $50 \%$ of MEN2B cases.

\section{Von Hippel-Lindau disease}

The frequency of pheochromocytomas in VHL patients ranges from 10 to $30 \%$ and is restricted to the type 2 kindreds. Type 1 VHL patients with renal cell carcinomas, hemangioblastomas and retinal angiomas do not usually develop pheochromocytomas.

\section{Neurofibromatosis type 1}

Pheochromocytomas are associated with $1-4 \%$ of NF1 patients. NF1 carries $100 \%$ disease penetrance within families. The prevalence of pheochromocytomas in NF1 patients is greater than that in the general population. ${ }^{51}$ 


\begin{tabular}{rr} 
& Adrenal tumors \\
\hline $\mathrm{S} 62$ & RV Lloyd
\end{tabular}
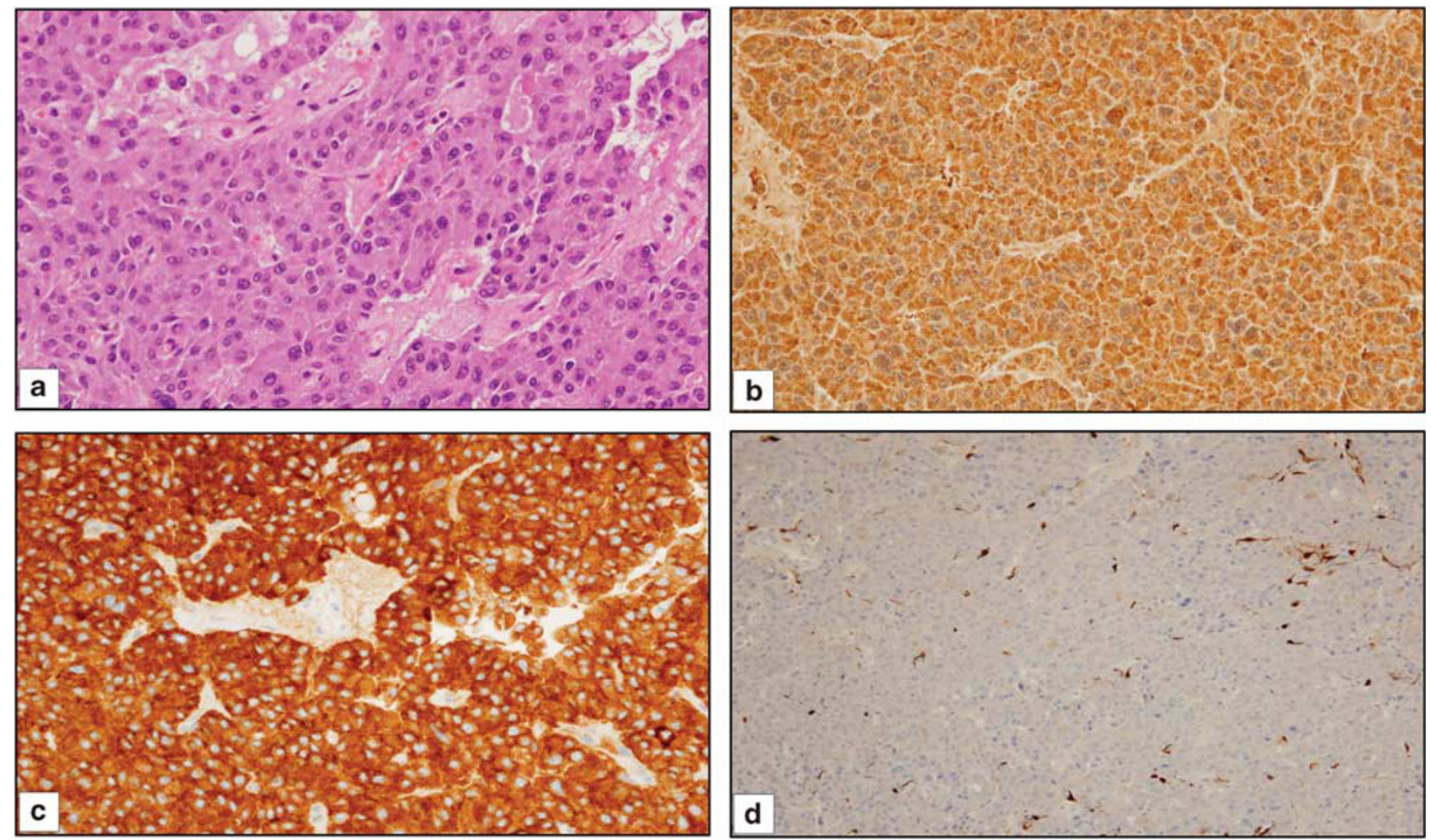

Figure 4 Retroperitoneal paraganglioma. (a) The H\&E section shows tumor cells with moderate amount of cytoplasm and small nuclei. (b) Chromogranin A immunostaining is diffusely positive in the tumor cells. Chromogranin A is present in the secretory granule. (c) Synaptophysin staining shows diffuse cytoplasmic staining in the tumor cells. (d) S100 acid protein stains the sustentacular cells in the tumor.

Table 1 Hereditary conditions associated with pheochromocytomas and paragangliomas

\begin{tabular}{lllll}
\hline Disorder & $\begin{array}{l}\text { Chromosome } \\
\text { location }\end{array}$ & Pheo & PGL & Genetics \\
\hline MEN 2A and 2B & 10q11.2 & + & & RET mutation \\
Von Hippel-Lindau & 3p26-29 & + & & VHL mutation \\
Neurofibromatosis I & $17 \mathrm{q} 11.2$ & + & & NF1 mutation \\
Familial PGL1 & 11q23 & & + & SDHD mutation \\
Familial PGL2 & $11 \mathrm{q} 13.1$ & & + & SDHAF2 \\
& & & & mutation \\
Familial PGL3 & 1q2 & & + & SDHC mutation \\
Familial PGL4 & 1q23-25 & + & + & SDHB mutation \\
\hline
\end{tabular}

Pheo, pheochromocytoma; PGL, paraganglioma; SDH, succinate dehydrogenase.

\section{Hereditary paraganglioma syndromes}

The frequency of succinate dehydrogenase B (SDHB) and SDHD mutations in pheochromocytomas is about $3-5 \%$. These mutations are much more common in paragangliomas or extra-adrenal pheochromocytomas. SDHB mutations have been associated with malignant paragangliomas (Table 1). Paragangliomas in the retroperitoneum are more likely to have SDHB mutations, and these are more commonly associated with malignancy. SDHC mutations are more common in head and neck paragangliomas that are usually benign. ${ }^{52}$ The most recently described SDH mutation is SDHAF2. ${ }^{52}$ The gene responsible for this mutation (PGL2) was initially termel SDHS. ${ }^{52}$

The distribution of genetic abnormalities between familial and sporadic pheochromocytomas and paragangliomas is also strikingly different. ${ }^{51}$ Recent studies have shown that immunohistochemical screening can be used to detect germ-line mutations of SDHB, SDHC and SDHD ${ }^{53}$ with the use of the antibodies reported by this group. DHAF2 mutations are associated with tumors of the head and neck region. ${ }^{1}$ The sporadic tumors stain positively, whereas tumors with germ-line mutations are negative (Figure $5 \mathrm{a}$ and $\mathrm{b}$ ). Molecular sequencing should be performed to validate the immunohistochemical findings. ${ }^{53}$

\section{Prognosis}

The usual prognosis of malignant pheochromocytomas is about 50\%/5-year survival. Some patients may have indolent disease with a life expectancy of more than 20 years.

\section{Molecular markers}

A series of molecular markers have been reported as markers of malignancy in pheochromocytomas. ${ }^{38}$ These include heat shock protein 9.0, human 

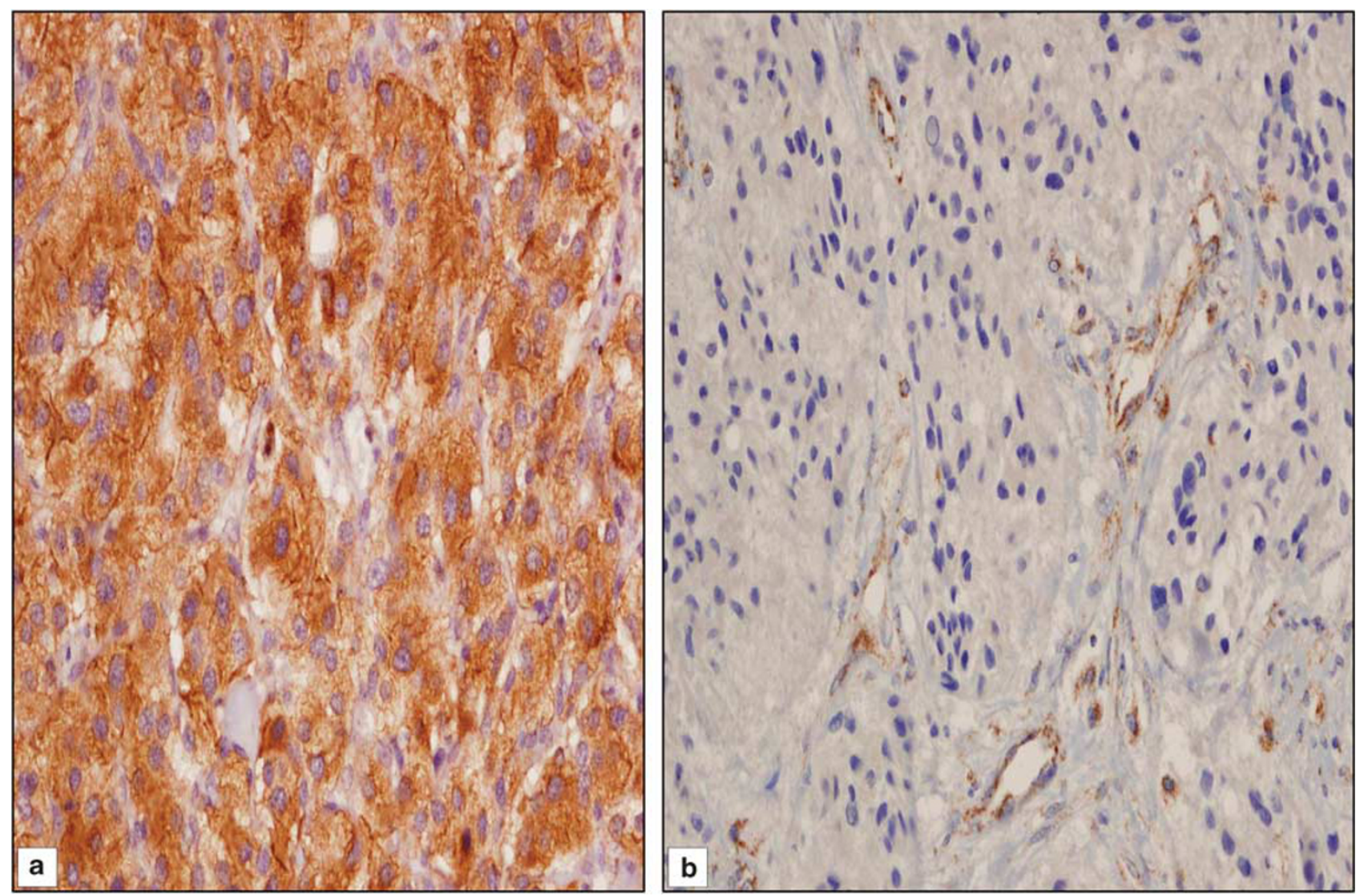

Figure 5 Paragangliomas immunostain for succinate dehydrogenase B (SDHB). (a) The wild-type tumor shows diffuse cytoplasmic staining in the tumor cells. (b) The tumor with an SDHB mutation shows absence of staining in the tumor cells, whereas the endothelial and a few stromal cells stain positively.

telomerase reverse transcriptase, vascular endothelial growth factor, vascular endothelial growth factor receptor hypoxia inducible factor $2-\alpha$, cyclooxygenase 2, tenascin $\mathrm{C}$, $\mathrm{N}$ cadherin- and secretogranin IIderived peptide EM66. The practical application of these markups will require more studies.

\section{Conclusions}

The Weiss criteria are commonly used to separate adrenal cortical adenomas from carcinomas. Adrenal cortical neoplasms in pediatric patients are more difficult to diagnose and it is more difficult to separate benign from malignant tumors in this age group. Oncocytic and myxoid variants of adrenal cortical tumors are uncommon. Different criteria are used to diagnose oncocytic adrenal cortical carcinomas. Pheochromocytomas and paragangliomas are usually positive for chromogranin and synaptophysin, whereas the sustentacular cells in both tumor groups are positive for $\mathrm{S} 100$ protein. A careful family history and molecular analyses are helpful in the workup and diagnosis of familial pheochromocytomas and paragangliomas. Mutations of the SDH gene family are associated with hereditary paraganglioma syndrome and SDHB mutations, which occur more commonly in retroperitoneal paragangliomas, are frequently associated with malignant tumors.

\section{Disclosure/conflict of interest}

The author declares no conflict of interest.

\section{References}

1 DeLellis RA, Lloyd RV, Heitz PU, et al. World Health Organization Classification of Tumors. Pathology and Genetics of Tumors of Endocrine Organs. IARC Press: Lyon, France 2004;137-146.

2 King DR, Lack EE. Adrenal cortical carcinoma: a clinical and pathologic study of 49 cases. Cancer 1979;44:239-244.

3 Symington T. The adrenal cortex. In: Symington T (ed). Functional Pathology of the Human Adrenal Glands. Williams \& Wilkins: Baltimore, 1969;3-216.

4 Tang CK, Harriman BB, Toker C. Myxoid adrenal cortical carcinoma: a light and electron microscopic study. Arch Pathol Lab Med 1979;103:635-638.

5 Sasano H, Suzuki T, Sano T, et al. Adrenocortical oncocytoma. A true non-functioning adrenocortical tumor. Am J Surg Pathol 1991;15:949-956. 
6 Gaffey MJ, Traweek ST, Mills SE, et al. Cytokeratin expression in adrenocortical neoplasia: an immunohistochemical and biochemical study with implications for the differential diagnosis of adrenocortical, hepatocellular, and renal cell carcinoma. Hum Pathol 1992;23:144-153.

7 Medeiros LJ, Weiss LM. New developments in the pathologic diagnosis of adrenal cortical neoplasm. A review. Am J Clin Pathol 1992;97:73-83.

8 Weiss LM. Comparative histologic study of 43 metastasizing and non-metastasizing adrenocortical tumors. Am J Surg Pathol 1984;8:163-169.

9 Lau SK, Weiss LM. The Weiss system for evaluating adenocortical neoplasms: 25 years later. Hum Pathol 2009;40:757-768.

10 Aubert S, Waremier A, Leroy X, et al. Weiss system revisited. A clinicopathologic and immunohistochemical study of 49 adrenocortical tumors. Am J Surg Pathol 2002;26:1612-1619.

11 van Slooten $\mathrm{H}$, Schaberg A, Smeenk D, et al. Morphologic characteristics of benign and malignant adrenocortical tumors. Cancer 1985;55:766-773.

12 Hough AJ, Hollifield JW, Page DL, et al. Prognostic factors in adrenal cortical tumors. A mathematical analysis of clinical and morphologic data. Am J Clin Pathol 1979;72:390-399.

13 Suzuki T, Sasano H, Nisikawa T, et al. Discerning malignancy in human adrenocortical neoplasm: utility of DNA flow cytometry and immunohistochemistry. Mod Pathol 1992;4:224-231.

14 Goldblum JR, Shannon R, Kaldjian EP, et al. Immunohistochemical assessment of proliferative activity in adrenocortical neopolasm. Mod Pathol 1993;6:663-668.

15 Kumar D, Kumar S. Adrenal cortical adenoma and adrenal metastasis of renal cell carcinoma: immunohistochemical and DNA ploidy analysis. Mod Pathol 1993;6:36-41.

16 Schrider S, Niendorf A, Achilles E, et al. Immunocytochemical differential diagnosis of adrenocortical neoplasm using the monoclonal antibody D11. Virchows Arch 1990;417:89-96.

17 Tartour E, Caillou B, Tenenbaum F, et al. Immunohistochemical study of adrenocortical carcinoma. Predictive value of the D11 monoclonal antibody. Cancer 1993;72:3296-3303.

18 Wick MR, Cherwitz DL, McGlennen RC, et al. Adrenocortical carcinoma. An immunohistochemical comparison with renal cell carcinoma. Am J Pathol 1986;122:343-352.

19 Vargas MP, Vargas HI, Kleiner DE, et al. Adrenocortical neoplasm: role of prognostic markers MIB-1, P53 and RB. Am J Surg Pathol 1997;21:556-562.

20 Sasano H, Suzuki T, Nagura H, et al. Steroidogenesis in human adrenocortical carcinoma: biochemical activities, immunohistochemistry, and in situ hybridization of steroidogenic enzymes and histopathologic study in nine cases. Hum Pathol 1993;24:397-404.

21 Sasano H, Shizawa S, Suzuki T, et al. Ad4BP in the human adrenal cortex and its disorders. J Clin Endocrinol Metab 1995;80:2378-2380.

22 Wieneke JA, Thompson LD, Heffess CS. Adrenal cortical neoplasm in the pediatric population: a clinicopathologic and immunophenotypic analysis of 83 patients. Am J Surg Pathol 2003;27:867-881.

23 el-Naggar AK, Evans DB, Mackay B. Oncocytic adrenal cortical carcinoma. Ultrastruct Pathol 1991;15: $549-556$.
24 Biscegha M, Ludovico O, Di Mattia A, et al. Adrenal oncocytic tumors: report of 10 cases and review of the literature. Int J Surg Pathol 2004;12:231-243.

25 Brown FM, Gaffey TA, Wold LE, et al. Myxoid neoplasms of the adrenal cortex: a rare histologic variant. Am J Surg Pathol 2000;24:396-401.

26 Erickson LS, Jin L, Sebo TJ, et al. Pathologic features and expression of insulin-like growth factor-2 in adrenocortical neoplasm. Endocr Pathol 2001;12: 429-435.

27 Stojadinuvic A, Ghossein RA, Hous A, et al. Adrenocortical carcinoma: clinical, morphologic and molecular characterization. J Clin Oncol 2002;20:941-950.

28 Giordano TJ, Thomas DG, Kuick R, et al. Distinct transcriptional profiles of adrenocortical tumors uncovered by DNA microarray analysis. Am J Pathol 2003;162:521-531.

29 Giordano TJ. Molecular pathology of adrenal cortical tumors: separating adenomas from carcinomas. Endocr Pathol 2006;17:355-364.

30 Velazquez-Fernandez D, Laurell C, Geli J, et al. Expression profiling of adrenal cortical neoplasms suggest a molecular signature of malignancy. Surgery 2005;138:1087-1094.

31 Suh I, Guerrero MA, Kebebew E. Gene-expression profiling of adrenocortical carcinoma. Expert Rev Mol Diagn 2009;9:343-351. Review.

32 Melicow MM. One hundred cases of pheochromocytoma (107 tumors) at the Columbia- Presbyterian Medical Center, 1926-1976: a clinicopathological analysis. Cancer 1977;40:1987-2004.

33 Modlin IM, Farndon JR, Shephers A, et al. Pheochromocytomas in 72 patients: clinical and diagnostic features, treatment and long term results. Br J Surg 1979;66:456-465.

34 Kimura N, Watanabe T, Noshiro T, et al. Histological grading of adrenal and extra-adrenal pheochromocytomas and relationship to prognosis: a clinicopathological analysis of 116 adrenal pheochromocytomas and 30 extra-adrenal sympathetic paragangliomas including 38 malignant tumors. Endocr Pathol 2005;16:23-32.

35 Linnoila RI, Keiser HR, Steinberg SM, et al. Histopathology of benign versus malignant sympathoadrenal paragangliomas: clinicopathologic study of 120 cases including unusual histologic features. Hum Pathol 1990;21:1168-1180.

36 Favier J, Plouin PF, Corvol P, et al. Angiogenesis and vascular architecture in pheochromocytomas: distinctive traits in malignant tumors. Am J Pathol 2002;161: 1235-1246.

37 Rooijens PP, de Krijger RR, Bonjer HJ, et al. The significance of angiogenesis in malignant pheochromocytomas. Endocr Pathol 2004;15:39-45.

38 Eisenhofer G, Bornstein SR, Brouwers FM, et al. Malignant pheochromocytoma: current status and initiatives for future progress. Endocr Relat Cancer 2004;11:423-436.

39 Allibhai Z, Rodrigues G, Brecevic E, et al. Malignant pheochromocytomas associated with germline mutation of the SDHB gene. J Urol 2004;172:1409-1410.

40 Pang LC, Tsao KC. Flow cytometric DNA analysis for the determination of malignant potential in adrenal and extra-adrenal pheochromocytomas or paragangliomas. Arch Pathol Lab Med 1993;117:1142-1147.

41 Bertherat J, Gimenez-Roqueplo AP. New insights in the genetics of adrenocortical tumors, pheochromocytomas 
and paragangliomas. Horm Metab Res 2005;37: 384-390.

42 Bravo EL. Evolving concepts in the pathophysiology, diagnosis and treatment of pheochromocytoma. Endocr Rev 1994;15:356-368.

43 Shapiro B, Sisson JC, Lloyd R, et al. Malignant pheochromocytoma: clinical, biochemical and scintigraphic characterization. Clin Endocrinol (Oxf) 1984; 20:189-203.

44 Pattarino F, Bouloux PM. The diagnosis of malignancy in pheochromocytoma. Clin Endocrinol (Oxf) 1996; 44:2390241.

45 Plouin PF, Chatelier G, Fofol I, et al. Tumor recurrence and hypertension persistence after successful pheochromocytoma operation. Hypertension 1997;29:1133-1139.

46 Thompson LD. Pheochromocytoma of the Adrenal Gland Scaled Score (PASS) to separate benign from malignant neoplasms: a clinicopathologic and immunophenotypic study of 100 cases. Am J Surg Pathol 2002;26:551-566.

$47 \mathrm{Wu}$ D, Tischler AS, Lloyd RV, et al. Observer variation in the application of the Pheochromocytoma of the Adrenal Gland Scaled Score. Am J Surg Pathol 2009;33:599-608.
48 Gao B, Meng F, Bien W, et al. Validation of Pheochromocytomas of the Adrenal Gland Scaled Score for predicting malignant pheochromocytomas. Urology 2006;68:282-286.

49 Tischler AS, Kimmura N, McNicol AM. Pathology of pheochromocytoma and extra-adrenal paraganglioma. Ann NY Acad Sci 2006;1073:557-576.

50 Zarheger R, Kebebew E, Duh Y-Y, et al. Malignant pheochromocytoma. Surg Oncol Clin N Am 2006;15: $555-571$.

51 Dannenberg H, Komminoth P, Dinjens WNM, et al. Molecular genetic alterations in adrenal and extraadrenal pheochromocytomas and paragangliomas. Endocr Pathol 2003;14:329-350.

52 Hao H-X, Khalimonchuk O, Shraders M, et al. SDH5 a gene required for flavinatin of succinate dehydrogenase, is mutated in paraganglioma. Science 2009;325: 1139-1142.

53 van Nederveen FH, Gaal J, Favier J, et al. An immunohistochemical procedure to detect patients with paraganglioma and phaeochromocytoma with germline SDHB, SDHC and SDHD gene mutations: a retrospective and prospective analysis. Lancet Oncol 2009;10:764-777. 